\title{
Salification process of human body in the Chehrabad salt mine using XRF and Psychrometric test
}

\section{Kamal Aldin Niknami, Mohamad Masoumian, Parisa Nekouei}

Department of Archaeology, University of Tehran, Enghlab Street, Tehran, Iran

\section{Email address:}

kniknami@ut.ac.ir (K. A. Niknami)

\section{To cite this article:}

Kamal Aldin Niknami, Mohamad Masoumian, Parisa Nekouei. Salification Process of Human Body in the Chehrabad Salt Mine using XRF and Psychrometric Test. International Journal of Archaeology. Vol. 2, No. 2, 2014, pp. 6-11. doi: 10.11648/j.ija.20140202.11

\begin{abstract}
In the past years, several corpses that remained intact in the course of history were found in the Chehrabad salt mine of Zanjan Province, Iran and were made use to conduct several interdisciplinary studies to answer the questions of this paper. As we may know, archeological findings are always exposed to destruction. The rate of destruction depends variably on the organic or mineral substances and materials, as well as the environmental factors. In the environments with saline soils like the archeological site of Chehrabad, the destruction rate makes it necessary to adopt a new approach for the study of destruction and protection of the data. Therefore, the six samples of the rock salt taken from this site were analyzed by XRF method and psychrometric tests. The results show that the different saline compositions and environmental conditions are effective in the protection or destruction of organic or mineral components. In addition, we concluded that the high purity of rock salt at this site (more than 99.5\%) and the very low moisture content of the environment were involved in the mummification of the buried corpses immediately after they were buried and thus prevented the activity of bacteria and other microorganisms that were the cause of decay.
\end{abstract}

Keywords: Chehrabad Salt Mine, Salt Men, Salt Mummies, XRF, Psychrometric Test

\section{Introduction}

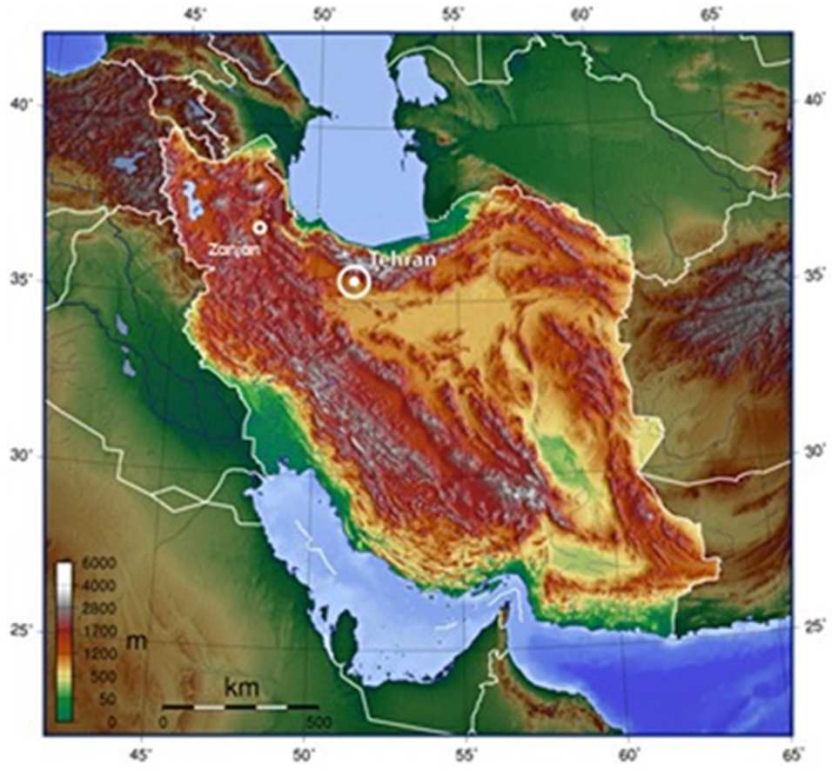

Map 1. Map of Iran, showing the location of Zanjan Province, (http://en.wikipedia.org/wiki/File:Iran_topo -_en.jpg).
Chehrabad salt mine is located $75 \mathrm{~km}$ northwest of Zanjan and $1 \mathrm{~km}$ south of Hamzelou village (Map 1). This region is situated within Qezel Uzan River basin. It is formed of rolling hills and heights within two narrow valleys (Aali et al. 2012). Mineberg is on one of the slopes of the hill, $1350 \mathrm{~m}$ high, and limited to Mehrabad and Chehrabad seasonal streams from east and south sides. According to the geological studies, this region was formed in the shallow lake basin in Miocene epoch.

In this basin, among sediments like marl and clay deposited with fine-grained gravels, evaporite minerals such as salt and gypsum are found in abundance. Chehrabad salt mine is indeed an outcrop made of sodium chloride evaporite deposits under a thick layer of red and green marls with the thickness of $40 \mathrm{~m}$ (Aali, 2006: 26). In geographical and geological terms, the salt mine is located in a vast semi-mountainous region with argillaceous and saline sediments. The exposure of crystalline rock salts and the presence of abundant and useful resources have attracted miners from the past to the present for the extraction and exploitation of salt as a valuable substance.

In comparison to other salt mines of Iran, the significance of Chehrabad mine of Zanjan is that several 
mummified corpses, many organic residues, and many interesting relics such as remains of a leg within a boot, parts of wood, stems of trees and shrubs, fragments of fabrics, ropes made of wool and leather, a walnut, etc. were found in this mine (Sobuti, 1997: 60). Due to their destructible nature, such relics are rarely found in other archeological sites, and if so, they were mostly in inappropriate conditions. In contrast, the saline environment of Chehrabad mine was ideal for keeping such organic materials safe and intact (Vatandoust \& Dehkordi, 1998: 73).

\section{The Background of Research}

In 1993, the miners found the remains of the upper part of the corpse of salt-man during mining of salt in the southwest part of Kuh-e Ma'dan. The corpse was called later Salt-Man No. 1 (Sobuti, 1997: 64, Fig. 1). According to the dating techniques conducted on the bones and textile samples, it was found that the Salt Man was dated to about 1,700 years ago, that is, the early time of Sassanid dynasty (RCCCR, 1998: 15).

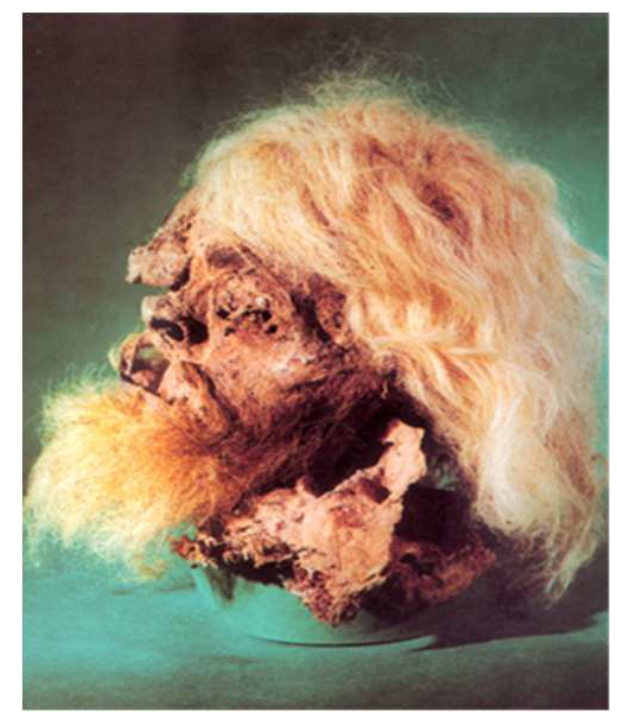

Fig. 1. Salt man number 1(RCCCR 2005:28).

More excavations and mining of salts was led to the discovery of Salt Man No. 2 in the fall of 2004 by the miners (Fig. 2). After a short time, Salt Man 3 was found. However, it was destroyed under bulldozer blades (Fig. 3). The mummy No. 2 was a middle-aged man $180 \mathrm{~cm}$ high with dark beard and hair. He died perhaps due to the collapse of the mine in the late Parthian era (Aali, 2006: 28). A major part of the soft tissues of the Salt Man 2 was destroyed and mostly all bones were separated under the bulldozer blades. However, some parts of the soft tissue remained on the bones of the hands, legs, and femur. The mummy No. 3 was also a middle-aged man with brown hair. He lived in the Achaemenian era and died under the rubbles of a tunnel, in which he worked (RCCCR, 1998: 17).

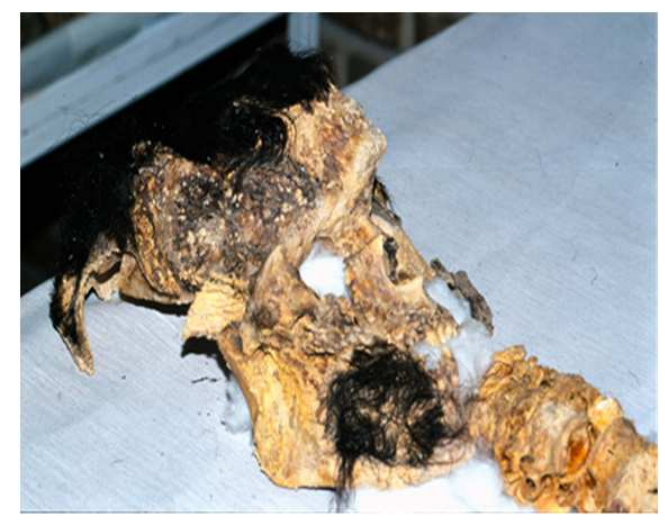

Fig. 2. Salt man number 2 (RCCCR 2005:3).

The accidental discovery in 2004 was a trigger in saving exploration in the salt mine. In the winter of the same year, the first exploration was begun in the location of findings of the Salt Man 2 and 3. In this season, in addition to many different relics including mining tools, herbal and animal remains, leather, and tile, the fourth naturally mummified corpse was found almost in an unharmed manner through the archeological excavations. The mummified corpse was a young boy, who died at the age of 16. Based on radiocarbon dating, the mummy No. 4 lived during Achaemenian period (2400-2300 years ago) (Shokouhi, 2005: 3 and Fig. 4).

The discovery of the Salt Man No. 5 was another valuable finding during the second season of explorations (Fig. 5). The remains of the Salt Man No. 5 were laid beneath huge rock salts. In contrast to the mummy No. 4 , the soft tissues of the corpse were decayed and destroyed because of the environmental conditions. The evidence indicated that water penetrated from the upper part of the mountain into this part of the mine and caused the destruction of the body (Aali, 2006: 28-37).

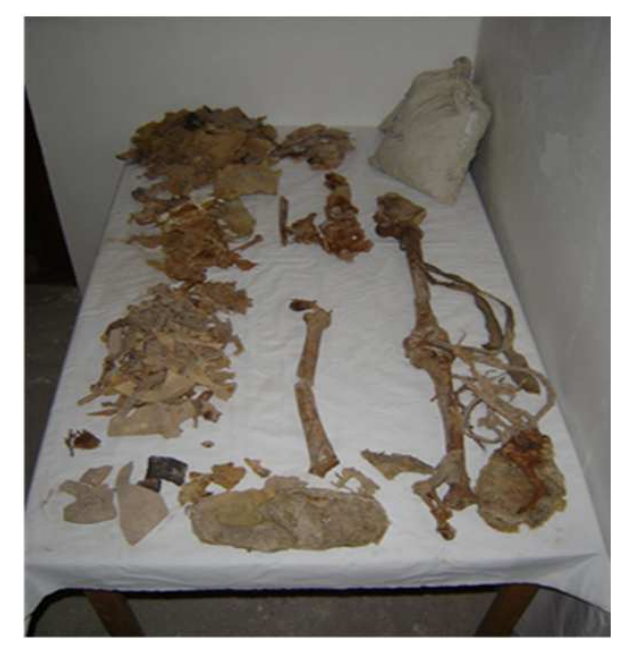

Fig. 3. Salt man number 3 (RCCCR 2005:28).

\section{The Decay Processes of Corpse}

After death, different tissues of human bodies start to decay at different rates based on their ingredients and 
resistance. For instance, the teeth and skeleton that are made of mineral substances are more resistant than other soft tissues of the body. Another example is the Hair cells that due to their special proteins within the cell walls become stronger and thicker than other cells.

The cells forming human body tissues are made mainly of proteins and lipoproteins. One of the causes of the body cell destruction is the cell nature itself. Another factor is the bacterial influences that exist within the human body or outside in the environment.

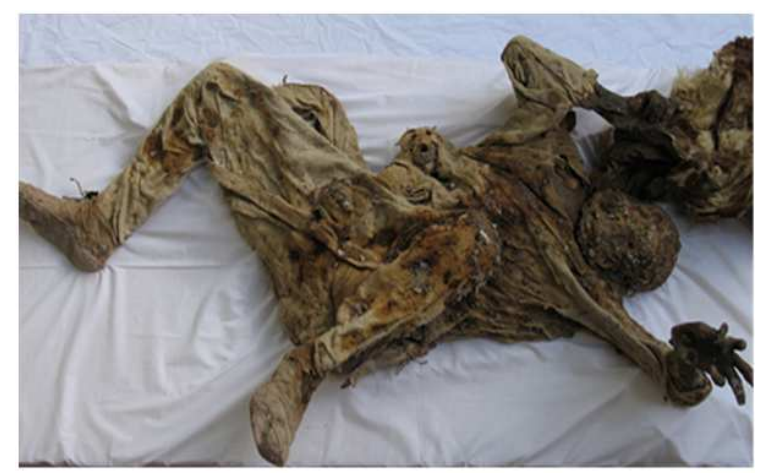

Fig. 4. Salt man number 4 (RCCCR 2005:18).

These unicellular organisms contain cell digestive enzymes that start to become active confronting the dead tissues. These digestive enzymes would actively function in the presence of water.

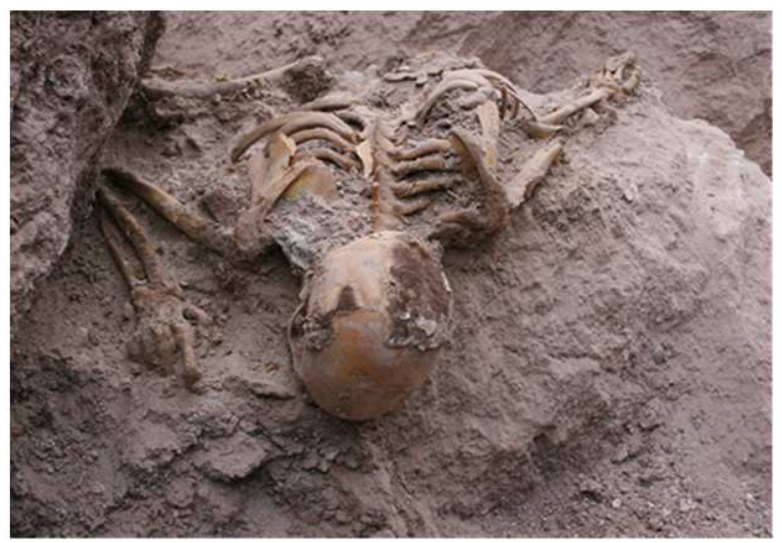

Fig. 5. Salt man number 5 (RCCCR 2005:16).

Therefore, the removal of water from cellular environments and external space may prevent the decomposition of cells by cellular components or bacteria. The removal of water may happen due to evaporation or in some cases due to the presence of the water absorbing materials. The corpses that are mummified accidentally in natural conditions may lose their moisture because of harsh sunlight, hot sands, wind, extreme cold, and salt marsh. The tissues of the corpses that are in saline conditions lose water and they are mummified under natural conditions causing their protections from the decomposition and destruction (Chamberlain and Parker Pearson, 2001).

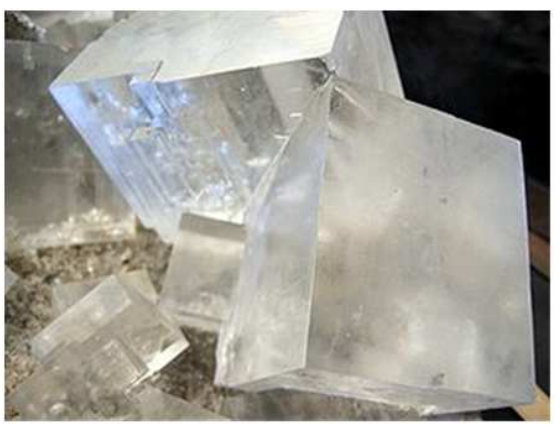

Fig. 6. The sample of Halite from the Chehrabad mine (Sorrell 1981:136).

\section{A Look at Salt Properties}

Salt or sodium chloride is a chemical compound made of sodium and chlorine elements. Sodium chloride is found in the form of cubic crystals, in which the larger negative chloride ions are separated by the presence of smaller positive sodium ions. Each ion is surrounded by six oppositely charged ions. This substance is the cause of the saltiness of oceans, seas, and extracellular fluids of multicellular organisms.

Sodium chloride is a vital substance which is highly hydrophilic and exists in body tissues and fluids. Solving nine percent of sodium chloride in water yields a physiological saline, which is very similar to blood plasma. Therefore, it is called a physiological solution. This fluid is used as an alternative in medicine. Its solubility is equal to 364 grams of sodium chloride in one liter of water (Johnsen, 2002).

Sodium chloride reduces the activity of water in biologic environments and acts as an effective preventer against decaying factors. Water activity refers to the freedom of water not participating in binding and accessible for the growth of microorganisms and chemical reactions. The ability of salt in reducing water activity is indeed the result of chloride and sodium ions in binding water molecules (Fennema, 1996; Potter and Hotchkiss, 1995). Also salt causes osmotic shock in microorganisms and decreases the intercellular water which further on leads to the cell death (Davidson, 1997). It has also been proven that salt restricts the solubility of oxygen in some microorganisms, and interferes in the function of enzymes or causes cells to use more energy to remove sodium ions. The above-mentioned phenomena can decrease the growth of microorganisms and prevents decomposition (Shelef and Seiter, 2005).

\section{The Factors Affecting the Function of Salt in the Process of Mummification}

Salt concentration: the high concentration of salt surrounding the corpse removes water from the body due to the osmotic pressure. Further on the salt penetrates into it. The removal of water restricts the growth of bacteria and the enzymatic activities, leading to the survival of the mummy. Salt purity: for rapid penetration, salt is required to be pure. 
Calcium and magnesium are the most common impurities of salt and may prevent the penetration of salt into muscle tissues. If salt is not penetrated into body tissues, the mummy will eventually decay (Wijnker et al. 2006).

\section{Sodium as the Main Substance Used for Mummification in Ancient Egypt}

In the ancient Egypt, natron which was a natural substance was abundantly used for the mummification of the corpse of kings. This natural salt was a mixture of sodium bicarbonate, sodium carbonate, and sodium chloride. In order to mummify, the Egyptians removed the internal organs of the corpse, and filled it with natron. Then, they covered the body with the mixture of natural resin and natron, or put the corpse in the solution of natron (Lucas, 2014: 73).

\section{Research Method}

The differences in the durability of the body tissues of Salt Man 4 and those of Salt Man 5 were made useful for our study and helped in answering to the following questions:

1-What are the elemental compositions and moisture of the rock salt within different parts of Chehrabad mine?

2-How can such compositions and moisture destroys or protects the relics existing in Chehrabad site or other similar sites?

$\mathrm{X}$-ray fluorescence (XRF) is an elemental analysis method used vastly in industry and research centers. This method is necessary in some special industries because it can recognize elements rapidly. In this method, $\mathrm{X}$-ray is emitted to the unknown sample. Because of the excitation of atoms, secondary X -ray is formed. The calculation of wavelength or the energy of secondary $\mathrm{X}$-ray can reveal the elements of the sample (Hadian Dehkordi, 2007: 89). L.O.I (i.e. loss on ignition) is a method used to calculate organic and volatile materials including water, carbon dioxide, and other volatiles removing the system.

Table 1. Chemical elements in the samples of rock salts (\%).

\begin{tabular}{ccccccc}
\hline & \multicolumn{3}{c}{ East Side of site A (\%) } & \multicolumn{3}{c}{ West Side of site A (\%) } \\
\hline \multirow{2}{*}{ Elements } & Sample & Sample & Sample & Sample & Sample & Sample \\
& $\mathbf{1}$ & $\mathbf{2}$ & $\mathbf{3}$ & $\mathbf{4}$ & $\mathbf{5}$ & $\mathbf{6}$ \\
\hline $\mathrm{Na}$ & 38.4 & 38.7 & 39.2 & 39.3 & 39.1 & 38.9 \\
$\mathrm{Mg}$ & 0.06 & 0.052 & 0.058 & 0.058 & 0.054 & 0.073 \\
$\mathrm{Al}$ & 0.13 & 0.13 & 0.11 & 0.16 & 0.11 & 0.33 \\
$\mathrm{SI}$ & 0.14 & 0.13 & 0.17 & 0.15 & 0.16 & 0.29 \\
$\mathrm{P}$ & 0.02 & 0.028 & 0.022 & 0.032 & 0.026 & 0.027 \\
$\mathrm{~S}$ & 0.15 & 0.16 & 0.14 & 0.1 & 0.15 & 0.18 \\
$\mathrm{CL}$ & 61.1 & 60.8 & 60.3 & 60.2 & 60.4 & 60.2 \\
\hline
\end{tabular}

Table 2. Percentage of evaporation in the samples.

\begin{tabular}{ccc}
\hline Place of sampling & sample & Percentage evaporated \\
\hline & 1 & 0.562 \\
East Side of site A (\%) & 2 & 0.574 \\
& 3 & 0.569 \\
West Side of site A (\%) & 4 & 0.6 \\
& 5 & 0.598 \\
& 6 & 0.605 \\
\hline
\end{tabular}

Table 3. $t$ student analysis to indicate significant differences among the chemical elements.

\begin{tabular}{|c|c|c|c|c|c|c|c|c|}
\hline & \multicolumn{2}{|c|}{$\mathrm{Na} \%$} & \multicolumn{2}{|c|}{$\operatorname{Mg} \%$} & \multicolumn{2}{|c|}{ Al \% } & \multicolumn{2}{|c|}{ CL\% } \\
\hline & East & West & East & west & East & west & East & west \\
\hline Mean & 38.767 & 39.1 & 0.057 & 0.062 & 0.123 & 0.2 & 60.733 & 60.267 \\
\hline Variance & $1.6 \times 10-1$ & $4.0 \times 10-2$ & $1.7 \times 10-5$ & $1.0 \times 10-4$ & $1.3 \times 10-4$ & $1.3 \times 10-2$ & $1.6 \times 10-1$ & $1.3 \times 10-2$ \\
\hline $\mathrm{P}(\mathrm{T}<=\mathrm{t})$ & \multicolumn{2}{|c|}{0.145} & \multicolumn{2}{|c|}{0.242} & \multicolumn{2}{|c|}{0.185} & \multicolumn{2}{|c|}{0.097} \\
\hline
\end{tabular}

EAST $=$ East Side of site A $\quad$ West=West Side of site A

For all chemical elements the amount of $\mathrm{p}$ is greater than the error range thus in $\% 95$ confidence level there is no significant difference among samples

Table 4. $t$ student analysis to indicate to probable significant differences of moisture in rock salts (\%95 confidence level).

\begin{tabular}{|c|c|c|}
\hline & East Side of site A (\%) & West Side of site A (\%) \\
\hline Mean & 0.658 & 0.601 \\
\hline Variance & $3.6 \times 10-5$ & $1.3 \times 10-5$ \\
\hline $\mathrm{P}(\mathrm{T}<=\mathrm{t})$ & \multicolumn{2}{|c|}{0.002} \\
\hline
\end{tabular}

EAST $=$ East Side of site A $\quad$ West $=$ West Side of site A

For all rock salts the amount of $\mathrm{p}$ lesser than the error range thus in $\% 95$ confidence level there is a significant difference of moisture between the two sides of site A.
In this research, three samples of rock salt were taken from the east side of the Site A (the surrounding areas of the mummy 4) and three samples from the west side of the Site A (the surrounding areas of Salt Man 5).

To recognize the elements of the samples of rock salt XRF method was employed. The moisture of the samples was measured by L.O.I method since all volatile substance in the rock salt is in the form of moisture. For our analyses of rock salts A11 basic Analytical Mill made by German Factory IKA and Memert Unbo 400 model were used. XRF elemental analysis was conducted in a semi-quantitative form, and the forming elements together with their weight percent were determined (Table 1).

The moisture of the samples was calculated base on the ratio of the weight of the sample after evaporation of volatiles to the initial weight by percent (Table 2). To study 
the hypotheses, the samples were divided into two groups of the east and west sides of the site A. To determine the significance of the difference between the two groups, Student's T-Test1 was employed (Table $3 \& 4$ ).

It must be noted that the above-mentioned tests were conducted in the microbiology lab of the faculty of science in Tehran University. The moisture test was conducted using the remains of the rock salt used for XRF test.

\section{Discussion and Conclusion}

According to the analyses, the main elements, which were recognized in Chehrabad salt mine, are sodium and chlorine. The ranges of change in sodium and chlorine were approximately similar in all samples, and no significant differences were observed between them. Other elements discovered were of very small amount. The analyses revealed that sodium and chlorine exist in high percentage. The results of the t-test confirmed expressly that the data of both groups are identical (Table $1 \& 3$ ).

In contrast to the elemental analyses, there was a significant difference between the samples of the rock salt of the east and west sides in terms of moisture (Table $2 \&$ 4). The moisture of the samples of the east side rock salt was significantly lower than that of the samples of the west side. The results of the t-test of the moisture data confirmed this claim (Table 4).

As mentioned above, one of the most important factors involved in the survivals of the mummified corpses is the velocity of salt penetration into the soft tissues. Such penetration depends on the purity of salt and the moisture of the environment. Considering the high purity of rock salts $(99.5 \%)$ and the very low moisture of the Chehrabad mine, the corpses were mummified properly and immediately after they were buried under the rubbles. Then the process of removing moisture from the corpse happened by osmotic process 2 and the rapid penetration of salt into the soft tissues This left no time for the growth of bacteria and enzymatic function in the corpse. According to the factors mentioned in this paper, there is approximately no opportunity for the growth and spread of any bacterium, larva, or decaying factors. The survival of the soft tissues and approximately the corpse of Salt Man 4, and many other organic relics seem to be the result of the aforementioned factors.

In contrast to Salt Man 4, the soft tissues of Salt Man 5 found in the west side of the Site A was mostly decayed and destroyed and only the soft tissues of a small part of the hands, feet as well as some parts of the face and hips were remained (Aali, 2006: 36-37). Considering the compositions of the rock salt throughout Site A, the only

\footnotetext{
${ }^{1}$. Student's T-Test evaluates the difference of the average of two independent groups.

${ }^{2}$. In the process of osmosis, water molecules penetrate from the parts with lower concentration to the part with higher concentration.
}

cause of decay was the environmental conditions of the Salt Man. The evidence shows that water penetrates from the upper part of the mountain to this part of the mine. The comparison of the results of psychrometry proved a significant difference between the moisture content of the samples of the east side of the site, and that of the west side. As the table 4 shows, the moisture content of the west side is to some extent higher than the east side. Bearing in mind that the stream flow within this region is changeable, it is possible that the moisture level of this area increased at some point in the course of history to an extent that microorganisms became active. In other words, after the corpse was buried under the rubble of the mine, it was affected by irregular moisture cycles and consequentially decayed However, since the process was irregular, those parts, from which salt was not removed, remained approximately safe and intact.

\section{References}

[1] Aali, A. 2006, Chehr Abad salt mine: report on new archaeological investigation in 2004-5, Archaeological Reports 5, 25-53.

[2] Aali, A., Abar, A., Boenke, N., Pollard, M., Ruhli, F., and Stollner, T., 2012, Ancient salt mining and salt men: The interdisciplinary Chehrabad Douzlakh project in northwestern Iran, Antiquity, vol.086, Issue 333.

[3] Chamberlain, A. T. and Parker Pearson, M., 2001, Earthly remains, the history and science of preserved human bodies, London, The British Museum Press.

[4] Fennema, O.R., (ed.), Food chemistry (3rd ed.), New York, Marcel Dekker Inc.

[5] Hadian Dehkordi 2007, Application of scientific investigations in conservation and restoration of historical buildings, Tehran, Tehran University Press.

[6] Davidson, P. M. 1997, Chemical preservatives and natural antimicrobial compounds, in M. P. Doyle, L. R. Beauchat, and T. J. Montville (eds.), Food microbiology: fundamentals and frontiers, Washington, DC, ASM Press, 520-556.

[7] Lucas, A. 2014, The use of natron in mummification, Journal of Egyptian Archaeology, 18 (3/4), 125-140.

[8] Johnsen, O., 2002, Minerals of the world, Princeton University Press.

[9] Potter, N. N., and Hotchkiss, J. H., 1995, Food science, (5th ed.), Food Science Texts Series, New York, Chapman \& Hall.

[10] RCCCR, 1998, Salt Man, Scientific investigations carried out on salt man mummified remains and its artifacts. Tehran: Research Center for Conservation of Culture Relics.

[11] Shelef, L. A., and J. Seiter 2005, Indirect and miscellaneous antimicrobials, in: P. M. Davidson, J. N. Sofos, and A. Larry. Branen (eds.), Antimocrobials in food (3rd ed.), Taylor and Francis, 573-598.

[12] Shokouhi, J.J., 2005, Radiographic report on Salt Man no. 4, unpublished manuscript, Iranian Center for Archaeological Research, ICHTO, Tehran. 
[13] Subouti, H., 1997, Preliminary report of Zanjan salt, Obituary Susa Archaeological Conference, Vol. 1, Iranian Center for Archaeological Research, ICHTO, Tehran.

[14] Vatandoust, A. and Hadian Dehkordi, M., 2005, Salt man, a new archaeological discovery: scientific investigation and conservation, in E.R. Massa (ed.), Proceedings of Fifth World
Congress on Mummy Studies, Turin, Italy, 2nd-5th September 2004, Journal of Biological Research 80, 236-42.

[15] Wijnkera, J.J., Koopb, G. and Lipmanb, L.J.A., 2006, Antimicrobial properties of salt $(\mathrm{Na} \mathrm{Cl})$ used for the preservation of natural casings, Food Microbiology 23, 657662 